\title{
Progress Toward Business Sustainability in Asia in the Aftermath of 2015 Hong Kong Stock Exchange Requirements
}

\author{
Zabihollah Rezaee ${ }^{1}$, Kevin Zhen ${ }^{2}$, Michael $\mathrm{Ha}^{3, *}$ \\ ${ }^{1}$ School of Accountancy, Fogelman College of Business and Economics, The University of Memphis, TN, USA \\ ${ }^{2}$ Sino-US College, Beijing Institute of Technology, Zhuhai, China \\ ${ }^{3}$ Department of Computer Science \& Technology, Sino-US College, Beijing Institute of Technology, Zhuhai, China \\ Email address: \\ Michael.Ha@suc.bitzh.edu.cn (M. Ha),maha2668@yahoo.com (M. Ha) \\ ${ }^{*}$ Corresponding author
}

\section{To cite this article:}

Zabihollah Rezaee, Kevin Zhen, Michael Ha. Progress Toward Business Sustainability in Asia in the Aftermath of 2015 Hong Kong Stock Exchange Requirements. International Journal of Sustainability Management and Information Technologies. Vol. 3, No. 4, 2017 , pp. 40-45. doi: $10.11648 /$ j.ijsmit.20170304.12

Received: September 20, 2017; Accepted: October 20, 2017; Published: November 10, 2017

\begin{abstract}
This paper examines the progress toward business sustainability in Asia in recent years. There are five dimensions of sustainability performance: Economic, Governance, Social, Ethical, and Environmental (EGSEE) and they collectively play an important role in the overall long-term success of business organizations. The role of business corporations in our society has evolved from profit maximization to creating shareholder value and in recent years to create shared value to protect interests of all stakeholders including investors, creditors, employees, customers, suppliers, government, the environment, and society. In today's business environment, global businesses are under close scrutiny and profound pressure from lawmakers, regulators, the investment community, and their various stakeholders to focus on sustainability measures and accept accountability and responsibility for the five EGSEE dimensions of their performance. Corporate performance is measured not only by the economic sustainability performance but also by a set of non-financial sustainability key performance indicators pertaining to environmental, social, governance, and ethical activities. In this paper, we investigate opportunities and challenges in implementing business sustainability in Asia and the progress toward integrated sustainability performance reporting and assurance. We conclude that much progress has been made in promoting business sustainability performance, reporting and assurance in Asia in recent years. However, much more needs to done in integrating business sustainability performance into business culture and corporate models in Asia. Integrated sustainability reporting and assurance also should be standardized in effectively, consistently, accurately, and reliably communicating all five dimensions of sustainability performance to all stakeholders.
\end{abstract}

Keywords: Governance, Environmental, Sustainability, Assurance, Reporting

\section{Introduction}

Business sustainability has been promoted for several decades as an integrated and holistic business model and strategic management to focus on the achievement of all five Economic, Governance, Social, Ethical, and Environmental (EGSEE) dimensions of sustainability performance in creating shared value for all stakeholders [1]. Currently, more than 14,000 public companies throughout the world are issuing sustainability reports on either a voluntary basis or mandatory on various EGSEE dimensions of sustainability performance [1]. The Global Reporting Initiative (GRI), in its initial Guidelines G3 and subsequently in its G4 guidelines, released in May 2013, promotes sustainability reporting as a standard practice of disclosing EGSEE sustainability performance dimensions relevant to companies and their stakeholders with the ethics dimension being integrated to other dimensions [2]. Brockett and Rezaee (2012) [3] report that until the late 1990's business sustainability disclosures have been largely voluntary with Finland being the first 
country to adopt a mandatory sustainability reporting law in 1997. Other countries that have adopted mandatory and semimandatory sustainability reporting are Australia, Austria, Canada, Denmark, France, Germany, Hong Kong, Malaysia, Netherlands, Sweden, and the United Kingdom. Particularly, the Hong Kong Stock Exchange, announced that an integrated sustainability and corporate governance reporting on some dimensions of sustainability performance is required for Hong Kong listed companies starting in 2015 and onwards [4]. Mandatory and standardized integrated sustainability reporting and assurance guidelines are needed to accurately, completely, and reliably communicate all five EGSEE dimensions of sustainability performance to all stakeholders. The United States' recent decision to exit the 2015 Paris Agreement, the 2015 landmark International Accord intended to combat climate change, is expected to encourage other countries (e.g., China, European, India) to step up providing leadership in sustainability initiatives, particularly in the environmental dimension of business sustainability including climate change and low carbon transition [5]. This paper examines the progress toward business sustainability performance, reporting and assurance in Asia in recent years and makes suggestions for the move toward a holistic and integrated sustainability performance, reporting, and assurance.

\section{Sustainability Performance}

Brockett and Rezaee (2012) [3] and Rezaee (2015) [6] classify sustainability performance into financial and nonfinancial performance and grouped into five dimensions of Economic (E), Governance (G), Social (S), Ethical (E), and Environmental (E), abbreviated as EGSEE. Scholarly research [1] [7] [8] dichotomizes the five EGSEE dimensions of sustainability to financial economic sustainability performance (ESP) and non-financial environmental, social, and governance (ESG) sustainability performance with the ethics dimension is integrated into both financial and nonfinancial dimensions of sustainability performance. In this section, consistent with Brockett and Rezaee (2012) [3] and Rezaee (2015) [6], we discuss five EGSEE dimensions of sustainability performance. Prior research (Rezaee) [6] suggests that there is a positive link between financial ESP and non-financial ESG including ethics. On one hand, companies that effectively manage their business can be financially sustainable and enable to improve non-financial ESG performance, fulfill their social responsibility, enhance their reputation, invest and attract in talented employees and promote a corporate culture of integrity and competency. On the other hand, companies that run their business ethically, focus on social and environmental initiatives and have strong corporate governance can be financially sustainable and generate sustainable performance, which add to their bottom line financial earnings. Nonetheless, tensions among ESP and ESG sustainability performance dimensions could exist as management is constrained by scarce resources, and has to be selective when deciding on the scope, extent, and type of
ESP and ESG initiatives. Given that the main objective function for any business organizations is to improve financial performance and they may engage in CSR activities merely to benefit their public image, prevent government intervention, gain government favor, or build better reputation with customers and society. In general, various dimensions of sustainability performance supplement each other and are not mutually exclusive. Companies that are governed effectively, are socially and environmentally responsible and conduct themselves ethically are expected to produce sustainable performance, create shareholder value and gain investor confidence and public trust. In this context, sustainability focuses on business activities that generate long-term ESP of firm value maximization as well as voluntary activities that result in the achievement of ESG sustainability performance that concerns all stakeholders.

\subsection{Economic Sustainability Performance}

Achievement of economic sustainability performance is the main objection function given that the primary goal of any business organization is to create shareholder value. Business sustainability requires that organizations focus on activities that generate long-term and sustainable corporate profitability rather than short-term performance. The economic dimension of sustainability performance can be achieved when business organizations focus on long-term sustainability performance and improved effectiveness, efficiency, and productivity of their operations. Long-term economic sustainability performance should be communicated to shareholders through the preparation of high-quality financial reports in compliance with global accounting standards as well as guidelines (G4) of the Global Reporting Initiative (GRI) Guidelines [2]. The economic dimension of sustainability performance should reflect the financial opportunities, strengths, challenges, risks, and concerns and an organization's activities and measured in terms of financial performance and disclosure attributes and their impacts on shareholder value creation. The KPMG 2013 Audit Committee Roundtable Report highlights the importance of long-term sustainable economic performance by suggesting that focusing on quarterly earnings can undermine a firm's long-term sustainable performance [9]. The 2013 KPMG report identifies the key measures of sustainable performance as operational efficiency, customer satisfaction, talent management, and innovation that should be derived from internal factors of strategy, risk profile, strengths and weaknesses, and corporate culture as well as external factors of reputation, technology, completion, globalization, and utilization of natural resources [9]. Achievement of economic sustainability performance requires understanding of the three financial attributes of performance, disclosure and risks and their integration into the corporate culture as well as management strategies, decisions, and actions. This integrated approach to sustaining business sustainability enables management to effectively compete in the global marketplace and create shareholder value. 


\subsection{Governance Dimension of Sustainability Performance}

The corporate governance landscape has changed significantly in the aftermath of the global 2007-2009 financial crises. The lack of effective corporate governance has been mentioned frequently as an overriding contributing factor in the global financial crises and the persistence of corporate failures in recent years. Internal and external corporate governance measures should be in place to improve the quality of corporate governance and thus stakeholder trust and investor confidence in corporate sustainable performance and reporting. Effective corporate governance requires an appropriate tone at the top, which promotes accountability for the board of directors and executives, enhances sustainable operational and financial performance, improves the reliability and quality of financial information, and strengthens the integrity and efficiency of the capital market. The achievement of effective governance dimension of sustainability performance requires clear definition and determinations of roles and responsibilities of all corporate gatekeepers from the board of directors to executives, internal auditors, external auditors, legal counsel and financial advisors. The effectiveness of corporate governance is affected by legal, regulatory, internal and external mechanisms, and best practices to create shareholder value while protecting the interests of other stakeholders. The corporate governance dimension of sustainability determines how effective a business organization is managed to create shared value for all stakeholders including shareowners.

\subsection{Social Dimension of Sustainability Performance}

The social dimension of sustainability performance is commonly referred to as corporate social responsibility (CSR) and often reflects the transformation of social goals into practices that benefit an organization's stakeholders. Social performance measures and presents an organization's social mission and its alignment with the interests of society in delivering products and services that are not detrimental to society. Socially responsible investment (SRI) is now practiced by many investors and becoming an increasingly important part of business and invest decisions. The United Nations Principles of Responsible Investing (PRI) were initiated in 2005 to promote global investors to integrate ESG into their investment decisions [10]. In recent years, under sustainable and socially responsible investing ("SRI") principles, investors consider various sustainability issues in their investment analyses, since SRI increased by more than 22 percent to $\$ 3.74$ trillion in managed assets during the 2010-2012 period [11].

\subsection{Ethical Dimension of Sustainability Performance}

An organization's ethical culture and practices can play an important role in promoting integrity and competency throughout the organization and in ensuring the achievement of both financial and non-financial sustainability performance. The effective achievement of ethical sustainability performance is determined by a corporate culture of integrity and competency and an appropriate tone at the top in promoting ethical behavior throughout the organization. Characteristics of an ethical organization culture are ethical workplace that promotes honesty, fairness, mutual respect, and freedom to raise concerns, establishment of codes of conduct for directors, officers, and employees and a system of responsibility and accountability to promote ethical behavior. The ethical dimension of sustainability performance should be integrated into corporate culture and business environment to improve quality and quantity of both financial and non-financial business activities and reports.

\subsection{Environmental Dimension of Sustainability Performance}

The environmental dimension of sustainability performance demands clear and transparent information about the impacts of an organization's activities and operations on the environment beyond what is mandated by law. The environmental dimension of sustainability performance includes creating a better work environment, improving air and water quality, reducing the carbon footprint and maximizing the positive effects of an organization on natural resources and the environment. Governments worldwide are instituting measures to ensure that the environment is better protected by the behest of society at large. Effective achievement of environmental sustainability performance requires business organizations often allow forego the economic benefits of their activities to ensure proper protection of the environment and to leave a better environment for the next generations. Climate change affects organizations of all types and sized worldwide and thus should be integrated into sustainability initiatives, decisions and actions.

\section{Sustainability Reporting}

The achievement of EGSEE sustainability performance requires management extend its focus beyond maximizing short-term shareholder profit by considering the impact of its operation and entire value chains on all stakeholders including the community, society, and the environment. Disclosure of EGSEE dimensions of sustainability performance while signaling management commitments to sustainability and establishing legitimacy with all constituencies poses a cost-benefit trade-off that has implications for investors and business organizations. In creating stakeholder value, management should identify potential social, environmental, governance and ethical issues of concern and integrate them into their strategic planning and managerial processes. Sustainability reporting is a process of identifying, classifying, measuring, realizing and reporting activities in all five EGSEE dimensions of sustainability performance [1].

The GRI was launched in 1997 to bring consistency and global standardization to sustainability reporting. GRI initially focused on incorporating environmental performance into corporate reporting with its "Sustainability Reporting 
Guidelines," which were published in 2000, 2002, 2006, 2011, and 2013. GRI is now considered the sole global standard-setter in sustainability reporting. The current version, the "G4 Guidelines," was issued in May 2013 [2]. In addition to including more data points in the disclosures from the previous version 3.1, G4 adds in a good number of disclosures in most aspects, particularly by adding the "Ethics and Integrity" element and substantially strengthening "Corporate Governance" measures.

Rezaee (2015) [6] suggests that sustainability reporting be promoted in following three ways:

1. Through market forces of the demand for and interest in EGSEE performance reporting by investors and financial markets.

2. Through mandatory sustainability reporting by regulators and listing standards of stock exchanges and European Parliament Directives to require large public companies in Europe to report on their social, governance, environmental, and diversity initiatives.

3. Through a combination of mandatory and voluntary initiatives.

Recently, Global Reporting Initiative provided a comprehensive Sustainability Reporting Framework to enable greater organizational transparency [2]. In 2013, the International Integrated Reporting Council (IIRC) developed the International Integrated Reporting Framework which provides guidelines for companies to integrate financial and non-financial performance information to benefit all stakeholders [14]. The European Parliament, on May 15, 2014 , issued a new directive that would require more than 6,000 listed European companies to disclose information on their environmental, social, and diversity in addition to financial information on economic performance for their 2017 reporting period [13]. It is expected that companies in other countries will follow suit and thus in the near future sustainability reports will reflect both financial and nonfinancial information relevant to all five EGSEE dimensions of sustainability performance, and assurance will be provided on these reports to enhance their credibility and reliability. An integrated sustainability report should not only provide information pertaining to financial performance and risks but also non-financial ESG performance and risks. A study conducted by Ernst and Young (EY) suggests that an integrated sustainability report can add value in many ways including improved reputation, increased employee loyalty, improved reliability of both financial and non-financial information, increased customer loyalty, improved relationships with all stakeholders including regulatory bodies, reduced risks and improved access to capital [15].

\section{Sustainability Assurance}

Currently, sustainability reports are voluntary and (normally) not audited by external auditors. Existing sustainability reports bear different names (green reporting, corporate social responsibility reporting), serve different stakeholders in achieving a variety of purposes, and vary in terms of content, structure, format, accuracy, and assurance. A more standardized, integrated, and audited process is required to make sustainability reports on EGSEE performance comparable, commonly acceptable, and relevant to all corporate stakeholders. Rezaee (2015) [6] states that assurance providers play an important role in providing assurance on sustainability reports reflecting all five EGSEE dimensions of sustainability performance. Objectivity, reliability, transparency, credibility, and usefulness of sustainability reports are important to both internal and external users of reports and can be enhanced by providing assurance on sustainability reports. Sustainability assurance can be provided internally by internal auditors or external assurance providers. While internal auditors are wellqualified to assist management in the preparation and assurance of sustainability reports, external users of sustainability reports may demand more independent and objective assurance on sustainability reports. This type of assurance can be provided by certified public accountants (CPAs), professional assurance providers, or equivalent accredited individuals, groups, or bodies. Current auditing standards are intended to provide reasonable assurance on financial and internal control reports prepared by management. However, the degree of reliance placed on nonfinancial information such as sustainability reporting is not clear. Assurance standards on different dimensions of sustainability performance reports vary in terms of rigorousness and general acceptability. For example, auditing standards governing reporting and assurance on economic activities presented in the financial statements are wellestablished, widely accepted, and practiced. Assurance standards on other dimensions of sustainability including governance, ethics, social, and environmental standards are yet to be fully-developed and globally accepted. External assurance is an important part of Integrated Reporting, as assurance providers verify the information contained in the reports and publish those conclusions so that others, generally less experienced in the particular dimensions in which said assurance providers have expertise, may be assured that the practices faithfully confirm the statements made by management.

\section{Sustainability Performance, Reporting and Assurance in Asia}

The United Nations (UN) released, in September 2015, a framework of the Sustainable Development Goals (SDGs) to address all three dimensions of economic development, social inclusion, and environmental sustainability and their integration into corporate culture and business environment worldwide. The European Commission [12] has long promoted business sustainability and its integration into corporate strategic decisions, and has recently required disclosure of environmental, social, and diversity information for more than 6,000 companies for their 2017 financial year [13]. Many countries in Asia are viewed as the most 
emerging financial markets and economies in the world. However, each country in Asia has its own corporate governance measures, CSR programs and sustainability initiatives that are shaped by its economic, cultural, political, and legal circumstances and affect its CSR activities. Particularly, corporate environment including corporate governance and CSR activities in China has evolved in the past several decades through the transformation of the socialist system into a market economy system. To promote market-based corporate governance and corporate financing, China established several stock exchange markets in Shanghai and Shenzhen in the early 1990s [16]. Thus, business sustainability performance has made substantial progress in Asia.

Disclosure of sustainability performance has become mandatory for companies listed on Hong Kong stock exchange since 2015 [4]. The Hong Kong Stock Exchange code provisions for sustainability reporting are detailed in [4]: Environmental, Social and Governance (ESG) Reporting Guide of the Hong Kong Stock Exchange Listing Rules for the Main Board listing companies. The Guide identifies general disclosure and key performance indicators on four ESG areas: Workplace Quality, Environment Protection, Operating Practices and Community Involvement in addition to Corporate Governance, which is covered [4] of the Main Board Listing Rules. The Exchange allows the company to specify the subject areas, aspects and indicators that are relevant and material in the context of its corporate strategy. As of date, the listing rules leave open the option for the companies to consider offering assurance on the ESG reports. The code on corporate governance reporting [4] of the Main Board Listing Rules came into effect in 2005. In April 2014, the Hong Kong Institute of Certified Accountants issued "A Guide on Better Governance Disclosure". The Hong Kong Stock Exchange has effectively integrated the reporting of sustainability with its earlier code requirements on Corporate Governance into the ESG Reporting. It is expected that more firms in China disclose their overall CSR strategies, activities, and performance as well as corporate governance. This move toward CSR sustainability in China is also expected to improve the content, depth, coverage and consistency of CSR reporting.

Listed companies in the Mainland China are now encouraged to report their business sustainability including CSR activities. In December 2008, the Shanghai and Shenzhen Stock Exchanges required a subset of Chinese listed firms to issue sustainability/CSR reports. This sustainability/CSR mandatory reporting policy affects CSR reporting for only a subset of Chines listed firms using a quasi-natural experiment [17]. The Rankins (PKS) is an independent rating agency, which has ranked and reported on CSR activities of listed companies in China in three broad categories of "macrocosm, content, and techniques since 2009. It is expected that more firms in China disclose their overall sustainability strategies, activities, and performance as well as corporate governance. This move toward sustainability performance reporting and assurance in China is also expected to improve the content, depth, coverage and consistency of sustainability reporting.

Using the Global Reporting Initiative database on sustainability reporting and assurance from 2005-2016 [2], we find that the quantity and quality of sustainability reporting and assurance have significantly improved in Asia in the past decade. We specifically find that: (1) the trend in the issuance sustainability reports in Asia from 2005-2016 has made substantial progress with the total of 10,377 reports and a majority $(71 \%)$ were published in the past five years; $(2)$ the trend in the issuance of sustainability assurance in Asia has made steady progress in the past five years; (3) the top three countries in Asia in terms of numbers of sustainability reports issued are Japan, followed by the Mainland China and Taiwan; (4) the top three countries in Asia in terms of numbers of sustainability assurance provided are Taiwan followed by Korea and then Japan; (5) the majority of sustainability reporting and assurance are in financial services, technology, equipment, and conglomerates industries; and (6) the quality of both sustainability reports and assurance has significantly improved in the past five years in Asia.

\section{Conclusions}

Business sustainability and sustainability performance are gaining global attention because corporations' goals have refocused from maximizing profit to creating shareholder value while protecting the interests of all stakeholders and still fulfilling their social responsibilities. Business sustainability has made significant progress from initial mere focus on CSR to its recent integration into corporate culture and business models worldwide in the past two decades. Sustainability performance in its five EGSEE dimensions is also becoming strategic imperative in Asia. Currently, sustainability reports in many Asian countries are voluntary and (normally) not audited by external auditors. Existing sustainability reports bear different names (green reporting, corporate social responsibility reporting), serve different stakeholders in achieving a variety of purposes, and vary in terms of content, structure, format, accuracy, and assurance. A more standardized, integrated, and audited process is required to make sustainability reports on EGSEE performance comparable, commonly acceptable, and relevant to all corporate stakeholders. Assurance providers play an important role in providing assurance on sustainability reports reflecting all five EGSEE dimensions of sustainability performance. Objectivity, reliability, transparency, credibility, and usefulness of sustainability reports are important to both internal and external users of reports and can be enhanced by providing assurance on sustainability reports.

\section{References}

[1] Rezaee, Z. (2016). Business sustainability research: A theoretical and integrated perspective. Journal of Accounting Literature 36 (2016): 48-64. 
[2] Global Reporting Initiative (GRI). 2013. G4 Exposure Draft. 2013. Frequently asked questions about the G4 Exposure Draft and the second G4 Public Comment Period. Available at https://www.globalreporting.org/resourcelibrary/G4-EDPCP2-FAQs.pdf.

[3] Brockett, A., \& Rezaee, Z. (2012). Corporate sustainability: integrating performance and reporting. John Wiley \& Sons, Hoboken, NJ, USA.

[4] Hong Kong Stock Exchange (HKEx). (2015). Appendix 27 Environmental, Social, and Governance Reporting Guide Introduction, 1 .

[5] Rucker, P. and J. Johnson. (2017). Trump Announced U. S. Will Exit Paris Climate deal, Sparking Criticism at Home and Abroad, June 1, 2017. Available at https://www.washingtonpost.com/politics/trump-to-announceus-will-exit-paris-climate-deal/2017/06/01/fbcb0196-46da11 e7-bcde-

624ad94170ab_story.html?utm_term=3d4aec4e1815.

[6] Rezaee, Z. 2015. Business sustainability: Performance, Compliance, Accountability and Integrated Reporting. Greenleaf Publishing Limited, October 2015.

[7] $\mathrm{Ng}$, A. C. and Z. Rezaee. 2015, Business sustainability performance and cost of equity capital. Journal of Corporate Finance, Vol. 34 (October): 128-149.

[8] Jain, P. K., Jain, A., \& Rezaee, Z. (2016). Value-relevance of corporate social performance: Evidence from Short Selling. Journal of Management Accounting Research. Vol. 28, No 2: 29-52.

[9] KPMG. 2013. Beyond Quarterly Earnings: Is the Company on Track for long-term success? Spring 2013 Audit Committee Roundtable Report. Available at auditcommittee@kpmg.com.

[10] United Nations Principles of Responsible Investing (UN PRI). 2005. The Fresh fields Report. Available at www.unepfi.org/fileadmin/documents/freshfields_legal_resp_ 20051123.pdf.
[11] Social Investment Forum (SIF). 2012. 2012 Report on sustainable and responsible investing trends in the United States, US SIF foundation: The forum for sustainable and responsible investment (November 2012). http://www.ussif.org/files/Publications/USSIF_2012AnnualRe port_F.pdf.

[12] United Nations (UN) Sustainable Development Goals report (UNSDGs). (2015), "Indicators and a Monitoring Framework for the Sustainable Development Goals Launching a data revolution for the SDGs", available at: http://unsdsn.org/wpcontent/uploads/2015/03/150320-SDSN-Indicator-Report.pdf (accessed 10 August 2017).

[13] European Commission. 2014. Disclosure of non-financial information: Europe information: Europe Council, the European Economic and Social, environmental issues. Available online at http://ec.europa.eu/internal_market/accounting/nonfinancial_reporting/index_en.htm, retrieved March 29, 2016.

[14] International Integrated Reporting Council (IIRC) (2015), "Assurance on Integrated Reporting (IR): Overview of Feedback and Call to Action, July 2015", available at: $\mathrm{http}: / /$ integratedreporting.org/wpcontent/uploads/2015/07/IIRC-Assurance-Overview-July2015.pdf (accessed 10 August 2017).

[15] Ernst and Young (EY). 2016. Value of Sustainability Reporting. Available at

http://www.ey.com/us/en/services/specialty-services/climatechange-and-sustainability-services/value-of-sustainabilityreporting.

[16] Lee, C. J. 2001. Financial Restructuring of State Owned Enterprises in China: The Case of Shanghai Sunve Pharmaceutical Corporation. Accounting, Organization and Society, Vol. 26, Issues 7-8: 263-280.

[17] Wang, X., Cao, F., \& Ye, K. 2016. Mandatory Corporate Social Responsibility (CSR) Reporting and Financial Reporting Quality: Evidence from a Quasi-Natural Experiment. Journal of Business Ethics, 1-22. 